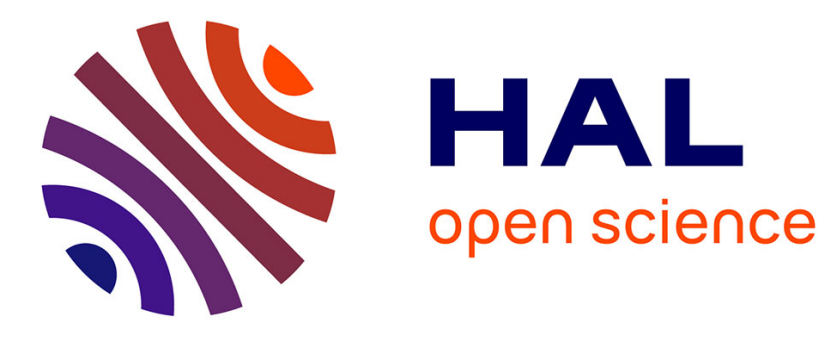

\title{
Lapsed derivations: Ternary stress in Harmonic Serialism
}

Francesc Torres-Tamarit, Peter Jurgec

\section{To cite this version:}

Francesc Torres-Tamarit, Peter Jurgec. Lapsed derivations: Ternary stress in Harmonic Serialism. Linguistic Inquiry, 2015. hal-01677773

\section{HAL Id: hal-01677773 \\ https://hal.science/hal-01677773}

Submitted on 8 Jan 2018

HAL is a multi-disciplinary open access archive for the deposit and dissemination of scientific research documents, whether they are published or not. The documents may come from teaching and research institutions in France or abroad, or from public or private research centers.
L'archive ouverte pluridisciplinaire HAL, est destinée au dépôt et à la diffusion de documents scientifiques de niveau recherche, publiés ou non, émanant des établissements d'enseignement et de recherche français ou étrangers, des laboratoires publics ou privés. 


\title{
Lapsed derivations: Ternary stress in Harmonic Serialism*
}

\author{
Francesc Torres-Tamarit, Vrije Universiteit Amsterdam \\ Peter Jurgec, University of Toronto
}

\section{Introduction}

Ternary stress presents a unique challenge to constraint-based metrical stress theories. The main question is how to model ternarity without ternary-specific representations, such as ternary feet. ${ }^{1}$ Along this line of reasoning, Elenbaas and Kager (1999) interpret ternarity as an underparsing effect in which long lapses are avoided while the number of feet is kept to a minimum. The standard constraint that prohibits long lapses is *LAPSE (1). This constraint is also known as *EXTENDEDLAPSE (Gordon 2002) or *LONGLAPSE (Kager 2007).

(1) *LAPSE (Elenbaas and Kager 1999)

Every weak beat must be adjacent to a strong beat or the word edge.

The constraint *LAPSE is a markedness constraint that disfavors sequences of three adjacent unstressed syllables (or moras). This constraint only triggers ternary rhythm when interacting with PARSE- $\sigma$ ( $\equiv$ Syllables must be footed) and the alignment constraints ALLFEET$\mathrm{R} / \mathrm{L}$.

To illustrate, let us look at Cayuvava, a ternary stress language (Key 1967). Cayuvava has stress on every third syllable counting from the right edge of the word, except in disyllabic words, which show initial stress (2). The pattern has been analyzed as right-to-left and trochaic, with an unparsed syllable between feet, and with final extrametricality (Hayes 1995). The rightmost foot has primary stress, whereas the other feet have secondary stress; in the analysis, we abstract away from this distinction. We will also not discuss any weight effects. 


$\begin{array}{lrrl}2 \sigma & (' \sigma \sigma) & \text { ('da.pa) } & \text { 'canoe' } \\ 3 \sigma & (' \sigma \sigma) \sigma & \text { ('to.mo)ho } & \text { 'small water container' } \\ 4 \sigma & \sigma(' \sigma \sigma) \sigma & \text { a('ri.po)ro } & \text { 'he already turned around' } \\ 5 \sigma & \sigma \sigma(' \sigma \sigma) \sigma & \text { a.ri('pi.ri)to } & \text { 'already planted' } \\ 6 \sigma & (' \sigma \sigma) \sigma(' \sigma \sigma) \sigma & \text { ('a.ri)hi('hi.be)e } & \text { 'I have already put the top on' } \\ 7 \sigma & \sigma(' \sigma \sigma) \sigma(' \sigma \sigma) \sigma & \text { ma('ra.ha)ha('e.i)ki } & \text { 'their blankets' } \\ 8 \sigma & \sigma \sigma(' \sigma \sigma) \sigma(' \sigma \sigma) \sigma & \text { i.ki('ta.pa)re('re.pe)ha } & \text { 'the water is clean' } \\ 9 \sigma & (' \sigma \sigma) \sigma(' \sigma \sigma) \sigma(' \sigma \sigma) \sigma & \text { ('tfa.a)di('ro.bo)Bu('ru.ru)tfe } & \text { 'ninety-nine' }\end{array}$

Consider an 8-syllable word, in which the first two syllables are left unparsed and only two non-adjacent feet surface (3). The alignment constraints prefer the fewest feet and rule out candidates (b) and (c) with three feet each. The remaining candidates differ in the position of the pair of unfooted syllables: the winning candidate (a) has this pair at the left edge, whereas candidate (d) has the unfooted syllables at the right edge of the word. However, only candidate (d) has a sequence of three unstressed syllables, violating the dominant *LAPSE constraint. We follow Elenbaas and Kager (1999) by using gradient alignment constraints; categorical alternatives are available and could be substituted without affecting the analyses in this squib (see McCarthy 2003, Hyde 2012a).

(3) Parallel analysis of an 8-syllable word (based on Elenbaas and Kager 1999)

\begin{tabular}{|lc||c|c|c|c|}
\hline & $/ \sigma \sigma \sigma \sigma \sigma \sigma \sigma \sigma /$ & *LAPSE & ALLFEET-L & ALLFEET-R & PARSE- $\sigma$ \\
\hline \hline a. & $\sigma \sigma\left({ }^{\prime} \sigma \sigma\right) \sigma\left({ }^{\prime} \sigma \sigma\right) \sigma$ & & $2+5$ & $1+4$ & 4 \\
\hline b. $\quad\left({ }^{\prime} \sigma \sigma\right)\left({ }^{\prime} \sigma \sigma\right) \sigma(' \sigma \sigma) \sigma$ & & $2+5$ & $1+4+6 \mathrm{~W}$ & $2 \mathrm{~L}$ \\
\hline c. & $\left({ }^{\prime} \sigma \sigma\right) \sigma\left({ }^{\prime} \sigma \sigma\right) \sigma(' \sigma \sigma)$ & & $3+6 \mathrm{~W}$ & $3+6 \mathrm{~W}$ & $2 \mathrm{~L}$ \\
\hline d. & $\sigma\left({ }^{\prime} \sigma \sigma\right) \sigma(' \sigma \sigma) \sigma \sigma$ & $1 \mathrm{~W}$ & $1+4 \mathrm{~L}$ & $2+5 \mathrm{~W}$ & 4 \\
\hline
\end{tabular}


The aim of this squib is to investigate how *LAPSE works in Harmonic Serialism (HS; McCarthy 2010a,b, to appear). Pruitt (2012) already uses a similar constraint against pairs of adjacent unstressed syllables to demonstrate that constraints referring to peaks and troughs make pathological predictions in HS. This is one of her arguments why HS requires footbased (rather than grid-based) representations and constraints. We complement her findings by demonstrating that *LAPSE, even under a ternary definition (2) and with foot-based representations, fails to produce ternary stress in HS. This shows that the problems with *LAPSE are persistent, arising under a variety of constraint definitions and representational assumptions. To make this point even more explicit, we show that the constraint *FoOTFoOT (Kager 1994)—which refers to footing rather than rhythm—predicts all four basic ternary stress systems and avoids the pathologies of *LAPSE.

We start by demonstrating that an HS analysis of Cayuvava using *LAPSE fails ( $(2)$. Then we show that adding FINAL-WINDOw into the constraint set does not save the analysis $(\S 3)$. After that, we look into pathologies caused by *LAPSE in HS (§4). All our claims are tested computationally using the typology calculator software OT-Help 2.0 (Staubs et al. 2010). We conclude that *LAPSE is incompatible with serialism. As an alternative, we propose a solution based on *FoоTFoоT ( $(5)$.

\section{Ternary stress in HS}

HS is a variant of OT that combines constraint ranking with serial derivations. Gen in HS generates only those candidates that differ from the input by one single operation. The winning candidate is then fed back to Gen as a new input for another round of evaluation. This loop is then repeated until the fully faithful parse of the latest input wins.

Let us briefly mention a few advantages of HS over parallel OT. First, it has long been recognized that phonological generalizations apply over intermediate forms between input and output. For example, footing sometimes ignores subsequent syncope, which can only 
be captured by grammars that can assign footing before applying syncope, such as HS (McCarthy 2010b). Second, variation in parallel OT is always assessed globally, that is, where all loci of violation within a form covary, whereas HS also predicts local variation, where each locus may vary independently. Both types of variation are attested (Kimper 2011). Third, positional faithfulness constraints in HS cannot be satisfied by moving the prominent position, which is a pathology of parallel OT (Jesney 2011).

Apart from these advantages, HS rules out pathological stress systems in which metrical parsing interacts non-locally with syllable weight, vowel shortening, and final syllable extrametricality, which are all predicted in parallel OT (Pruitt 2010). This suggests that HS might be preferred for footing systems in general over parallel OT. Consider now a 7-syllable word in Cayuvava (4). We follow Pruitt by assuming that Gen can build at most one foot at a time. The first foot will be built as close to the right edge as possible, while still minimally violating *LAPSE. The ranking *LAPSE $\gg$ ALLFEET-R rules out candidate (c) with perfect alignment. The two remaining candidates tie with respect to *LAPSE. Candidate (a) is selected over candidate (b) because of the ranking ALLFEET-R $\gg$ ALLFEET-L. ${ }^{2}$

Step 1

\begin{tabular}{|lr||c:c|c|c|}
\hline & $/ \sigma \sigma \sigma \sigma \sigma \sigma \sigma /$ & *LAPSE & PARSE- $\sigma$ & ALLFEET-R & ALLFEET-L \\
\hline \hline a. & $\sigma \sigma \sigma \sigma\left({ }^{\prime} \sigma \sigma\right) \sigma$ & 2 & 5 & 1 & 4 \\
\hline b. & $\sigma \sigma \sigma\left({ }^{\prime} \sigma \sigma\right) \sigma \sigma$ & 2 & 5 & $2 \mathrm{~W}$ & $3 \mathrm{~L}$ \\
\hline c. & $\sigma \sigma \sigma \sigma \sigma(' \sigma \sigma)$ & $3 \mathrm{~W}$ & 5 & $\mathrm{~L}$ & $5 \mathrm{~W}$ \\
\hline
\end{tabular}

The critical point comes at the second step, which is also the step before convergence. The ranking between the two alignment constraints obtained at the first step is at odds with the ranking required at the second step. At step 2, *LAPSE (along with ALLFEET-R) predicts ternarity if more than four syllables remain unparsed to the left of the most recently built foot. However, the problem arises when four or fewer syllables remain unparsed. In these 
cases, *LAPSE is satisfied by building a foot adjacent to the foot built at the previous step (5). This footing is preferred by the higher-ranked alignment constraint, here ALLFEET-R (5-a). Thus, *LAPSE cannot generate ternary stress in HS. This problem persists even under the other known alternatives to *LAPSE (Das 2001, Gordon 2002, Houghton 2008).

Step 2

\begin{tabular}{|c|c|c|c|c|}
\hline$|\sigma \sigma \sigma \sigma(' \sigma \sigma) \sigma|$ & $*$ LAPSE & PARSE- $\sigma$ & ALLFEET-R & ALLFEET-L \\
\hline a. $\sigma \sigma\left({ }^{\prime} \sigma \sigma\right)\left({ }^{\prime} \sigma \sigma\right) \sigma$ & & 3 & $1+3$ & $2+4$ \\
\hline b. $\odot \sigma\left({ }^{\prime} \sigma \sigma\right) \sigma\left({ }^{\prime} \sigma \sigma\right) \sigma$ & & 3 & $1+4$ & $1+4$ \\
\hline c. $\quad\left({ }^{\prime} \sigma \sigma\right) \sigma \sigma\left({ }^{\prime} \sigma \sigma\right) \sigma$ & 1 & 3 & $1+5$ & 4 \\
\hline d. $\quad \sigma \sigma \sigma \sigma\left({ }^{\prime} \sigma \sigma\right) \sigma$ & 2 & 5 & 1 & 4 \\
\hline
\end{tabular}

\section{FinAL-WINDOW}

The ranking between the two alignment constraints is the source of the problem in the current HS analysis with *LAPSE, because contradictory rankings are needed at step 1 and 2. To overcome this ranking paradox, an anonymous reviewer suggests reversing the ranking of alignment constraints (ALLFEET-L $\gg$ ALLFEET-R) and adding another constraint: FinAL-Window (Kager 2012, Hyde 2012a, see also Green and Kenstowicz 1995, van der Hulst 2010). This constraint requires that at least one of the last three syllables is stressed. At step 1, the top-ranked FINAL-WINDOW makes sure that the first foot is within the last three syllables, regardless of the ranking of the alignment constraints. FINAL-WINDOW is innocuous at further steps (6). At step 2, ALLFEET-L is decisive in selecting candidate (a) with no adjacent feet. Thus, ternary stress obtains. 


\begin{tabular}{|lc||c:c|c|c|}
\hline & $/ \sigma \sigma \sigma \sigma\left({ }^{\prime} \sigma \sigma\right) \sigma /$ & FINAL-WINDOW & *LAPSE & ALLFEET-L & ALLFEET-R \\
\hline \hline a. & $\sigma\left({ }^{\prime} \sigma \sigma\right) \sigma\left({ }^{\prime} \sigma \sigma\right) \sigma$ & & & $1+4$ & $1+4$ \\
\hline b. $\quad \sigma \sigma\left({ }^{\prime} \sigma \sigma\right)\left({ }^{\prime} \sigma \sigma\right) \sigma$ & & & $2+4 \mathrm{~W}$ & $1+3 \mathrm{~L}$ \\
\hline c. $\quad\left({ }^{\prime} \sigma \sigma\right) \sigma \sigma\left({ }^{\prime} \sigma \sigma\right) \sigma$ & & $1 \mathrm{~W}$ & $4 \mathrm{~L}$ & $1+5 \mathrm{~W}$ \\
\hline d. $\quad \sigma \sigma \sigma \sigma\left({ }^{\prime} \sigma \sigma\right) \sigma$ & & $2 \mathrm{~W}$ & $4 \mathrm{~L}$ & $1 \mathrm{~L}$ \\
\hline
\end{tabular}

Surprisingly, it looks like this ranking maintains the right-to-left directionality. However, this is just an illusion that becomes obvious in longer words (7). In a 9-syllable word, the candidates (a) and (b) tie on *LAPSE but differ with respect to the number of syllables between feet; ALLFEET-L prefers the wrong candidate (b) with two intervening unparsed syllables.

Step 2 in a 9-syllable word

\begin{tabular}{|c|c|c|c|c|}
\hline $\mid \sigma \sigma \sigma \sigma \sigma \sigma\left({ }^{\prime} \sigma \sigma\right) \sigma /$ & FINAL-WINDOW & *LAPSE & ALLFEET-L & AlLFEET-R \\
\hline a. $: ; \sigma \sigma \sigma\left({ }^{\prime} \sigma \sigma\right) \sigma\left({ }^{\prime} \sigma \sigma\right) \sigma$ & & 1 & $3+6$ & $1+4$ \\
\hline b. $\sigma \sigma\left({ }^{\prime} \sigma \sigma\right) \sigma \sigma\left({ }^{\prime} \sigma \sigma\right) \sigma$ & & 1 & $2+6$ & $1+5$ \\
\hline c. $\quad \sigma\left({ }^{\prime} \sigma \sigma\right) \sigma \sigma \sigma\left({ }^{\prime} \sigma \sigma\right) \sigma$ & & 2 & $1+6$ & $1+6$ \\
\hline d. $\quad\left({ }^{\prime} \sigma \sigma\right) \sigma \sigma \sigma \sigma\left({ }^{\prime} \sigma \sigma\right) \sigma$ & & 3 & 6 & $1+7$ \\
\hline
\end{tabular}

The ranking creates a bidirectional stress system. In HS, bidirectionality involves building one foot from one edge and the remaining feet from the opposite edge. While bidirectional stress systems are attested, the current one does not resemble any of them. ${ }^{3}$ At step 2, *LAPSE and alignment prefer a foot that is two syllables away from the left edge as long as the word has at least 9 syllables (7-b). At step 3, the intervening two syllables are footed under the pressure of *LAPSE (8). This creates a binary pattern in an otherwise ternary stress language. 
Step 3 in a 9-syllable word

\begin{tabular}{|r||c:c|c|c|}
\hline$/ \sigma \sigma\left({ }^{\prime} \sigma \sigma\right) \sigma \sigma\left({ }^{\prime} \sigma \sigma\right) \sigma /$ & FINAL-WINDOW & *LAPSE & ALLFEET-L & ALLFEET-R \\
\hline \hline a. ${ }^{\prime 2} \sigma \sigma\left({ }^{\prime} \sigma \sigma\right)\left({ }^{\prime} \sigma \sigma\right)\left({ }^{\prime} \sigma \sigma\right) \sigma$ & & & $2+4+6$ & $1+3+5$ \\
\hline b. $\quad \sigma \sigma\left({ }^{\prime} \sigma \sigma\right) \sigma \sigma\left({ }^{\prime} \sigma \sigma\right) \sigma$ & & $1 \mathrm{~W}$ & $2+6 \mathrm{~L}$ & $1+5 \mathrm{~L}$ \\
\hline
\end{tabular}

In short, Cayuvava cannot be modeled with FINAL-WINDOW in combination with *LAPSE; the problem with alignment constraints persists.

\section{Pathologies}

To make sure that *LAPSE is the cause of the problem in HS, we made use of the typology calculator software OT-Help 2.0 (Staubs et al. 2010). OT-Help 2.0 requires a user-defined set of inputs, Gen-operations, and constraints. Our inputs contained from 2 to 10 syllables, the only operation was to add a binary foot (iamb or trochee), and we used the following constraints: Trochee, Iamb, AllFeet-L, Allfeet-R, Parse- $\sigma$ and *Lapse. The software generated 39 languages. Of those, 15 generated languages lacked parsing in some words (and can be excluded on principle, e.g. by culminativity; Liberman and Prince 1977, Hayes 1995), 4 were attested single stress systems, and 4 were attested binary systems. The remaining 16 languages are all pathological and none even remotely resemble Cayuvava, or any other ternary stress language. To illustrate the extent of the pathologies of *LAPSE in HS, we now present a predicted language that mixes binarity and ternarity, and exhibits stress clash.

The default foot type in this language is trochaic, which surfaces in 2- and 3-syllable words. In longer words, 4 unparsed syllables cause a foot reversal (9), whereas 5 unparsed syllables or more cause additional misalignment at the left edge at the first step (10). Both foot reversal and misalignment best satisfy top-ranked *LAPSE. 
(9) Step 1 for a 4-syllable word

\begin{tabular}{|lc||c|c|c:c:c|c|}
\hline & $/ \sigma \sigma \sigma \sigma /$ & *LAPSE & AllFEet-L & AllFEET-R & PARSE- $\sigma$ & TROCHEE & IAMB \\
\hline \hline a. ${ }^{\prime 2}\left(\sigma^{\prime} \sigma\right) \sigma \sigma$ & & & 2 & 2 & 1 & \\
\hline b. $\quad \sigma\left({ }^{\prime} \sigma \sigma\right) \sigma$ & & $1 \mathrm{~W}$ & $1 \mathrm{~W}$ & 2 & $\mathrm{~L}$ & $1 \mathrm{~W}$ \\
\hline c. $\quad\left({ }^{\prime} \sigma \sigma\right) \sigma \sigma$ & $1 \mathrm{~W}$ & & 2 & 2 & $\mathrm{~L}$ & $1 \mathrm{~W}$ \\
\hline
\end{tabular}

(10) Step 1 for a 5-syllable word

\begin{tabular}{|lc||c|c|c:c:c|c|}
\hline & $/ \sigma \sigma \sigma \sigma \sigma /$ & $*$ LAPSE & AllFeET-L & AllFEET-R & PARSE- $\sigma$ & TROCHEE & IAMB \\
\hline \hline a. ${ }^{\prime} \sigma\left(\sigma^{\prime} \sigma\right) \sigma \sigma$ & & 1 & 2 & 3 & 1 & \\
\hline b. $\quad \sigma\left({ }^{\prime} \sigma \sigma\right) \sigma \sigma$ & $1 \mathrm{~W}$ & 1 & 2 & 3 & $\mathrm{~L}$ & $1 \mathrm{~W}$ \\
\hline c. $\quad\left(\sigma^{\prime} \sigma\right) \sigma \sigma \sigma$ & $1 \mathrm{~W}$ & $\mathrm{~L}$ & $3 \mathrm{~W}$ & 3 & 1 & \\
\hline
\end{tabular}

These generalizations are true at any step. After each foot is built, the following steps act as if the previous steps never happened. This way, with 3 unparsed syllables left, neither foot reversal nor misalignment occur, thus creating a stress clash in 6-syllable words (11).

(11) Step 2 for a 6-syllable word

\begin{tabular}{|lr||c|c|c:c:c|c|}
\hline & \multicolumn{1}{|c|}{$\sigma\left(\sigma^{\prime} \sigma\right) \sigma \sigma \sigma /$} & *LAPSE & ALLFEET-L & ALLFEET-R & PARSE- $\sigma$ & TROCHEE & IAMB \\
\hline \hline a. ${ }^{\prime} \sigma\left(\sigma^{\prime} \sigma\right)\left({ }^{\prime} \sigma \sigma\right) \sigma$ & & $1+3$ & $1+3$ & 2 & 1 & 1 \\
\hline b. $r\left(\sigma^{\prime} \sigma\right)\left(\sigma^{\prime} \sigma\right) \sigma$ & & $1+3$ & $1+3$ & 2 & $2 \mathrm{~W}$ & $\mathrm{~L}$ \\
\hline c. & $\sigma\left(\sigma^{\prime} \sigma\right) \sigma\left({ }^{\prime} \sigma \sigma\right)$ & & $1+4 \mathrm{~W}$ & $3 \mathrm{~L}$ & 2 & 1 & 1 \\
\hline
\end{tabular}

With 4 unparsed syllables left, binarity arises by reversing the basic foot type, thus creating a binary rhythm in 7-syllable words (12). 


\begin{tabular}{|lr||l|c|c|c|c|c|}
\hline & $/ \sigma\left(\sigma^{\prime} \sigma\right) \sigma \sigma \sigma \sigma /$ & *LAPSE & ALLFEET-L & AlLFEET-R & PARSE- $\sigma$ & TROCHEE & IAMB \\
\hline \hline a. & $\sigma\left(\sigma^{\prime} \sigma\right)\left(\sigma^{\prime} \sigma\right) \sigma \sigma$ & & $1+3$ & $2+4$ & 3 & 2 & \\
\hline b. & $\sigma\left(\sigma^{\prime} \sigma\right) \sigma\left(\sigma^{\prime} \sigma\right) \sigma$ & & $1+4 \mathrm{~W}$ & $1+4 \mathrm{~L}$ & 3 & 2 & \\
\hline c. & $\sigma\left(\sigma^{\prime} \sigma\right) \sigma(' \sigma \sigma) \sigma$ & & $1+4 \mathrm{~W}$ & $1+4 \mathrm{~L}$ & 3 & $1 \mathrm{~L}$ & $1 \mathrm{~W}$ \\
\hline d. & $\sigma\left(\sigma^{\prime} \sigma\right)\left({ }^{\prime} \sigma \sigma\right) \sigma \sigma$ & $1 \mathrm{~W}$ & $1+3$ & $2+4$ & 3 & $1 \mathrm{~L}$ & $1 \mathrm{~W}$ \\
\hline
\end{tabular}

Finally, with 5 or more unparsed syllables left, both misalignment and foot reversal obtain, resulting in ternarity in 8-syllable words (13).

(13) Step 2 for an 8-syllable word

\begin{tabular}{|lr||c|c|c:c:c|c|}
\hline & $/ \sigma\left(\sigma^{\prime} \sigma\right) \sigma \sigma \sigma \sigma \sigma /$ & *LAPSE & AllFeET-L & AllFeEt-R & PARSE- $\sigma$ & TROChEe & IAMB \\
\hline \hline a. & $\sigma\left(\sigma^{\prime} \sigma\right) \sigma\left(\sigma^{\prime} \sigma\right) \sigma \sigma$ & & $1+4$ & $2+5$ & 4 & 2 & \\
\hline b. & $\sigma\left(\sigma^{\prime} \sigma\right) \sigma(' \sigma \sigma) \sigma \sigma$ & $1 \mathrm{~W}$ & $1+4$ & $2+5$ & 4 & $1 \mathrm{~L}$ & $1 \mathrm{~W}$ \\
\hline c. & $\sigma\left(\sigma^{\prime} \sigma\right)\left(\sigma^{\prime} \sigma\right) \sigma \sigma \sigma$ & $1 \mathrm{~W}$ & $1+3 \mathrm{~L}$ & $3+5 \mathrm{~W}$ & 4 & 2 & \\
\hline d. & $\sigma\left(\sigma^{\prime} \sigma\right)\left({ }^{\prime} \sigma \sigma\right) \sigma \sigma \sigma$ & $2 \mathrm{~W}$ & $1+3 \mathrm{~L}$ & $3+5 \mathrm{~W}$ & 4 & $1 \mathrm{~L}$ & $1 \mathrm{~W}$ \\
\hline
\end{tabular}

To sum up, the pathology involves mixed binarity and ternarity, and stress clash, all of which blend as a function of the number of unparsed syllables at any step. This kind of strictly local ternarity, where rhythm is evaluated for a portion of the string, is unattested.

\section{5 *FOOTFOOT}

As we have seen, the constraint *LAPSE cannot generate ternary stress in HS ( $§ 2$ and $\S 3$ ) and predicts pathological patterns $(\S 4)$. This is because *LAPSE refers to rhythm, which is incompatible with serialism. If so, ternary stress will have to be captured by constraints that do not refer to rhythm. This point will be illustrated on the constraint *FOOTFOOT (三 No adjacent feet; Kager 1994). ${ }^{4}$

The constraint *FOOTFOOT works in a completely different way than *LAPSE. Because 
*FoOTFoOT refers to two feet, any form with a single foot will vacuously satisfy this constraint. Hence, *FоOTFoOT is always satisfied at the first step (14). The position of the first foot is entirely up to other constraints.

Consider again Cayuvava. First, the ranking ALLFEET-R $\gg$ ALLFEET-L rules out candidate (c) with initial stress. Second, an additional constraint is needed to obtain antepenultimate stress. We use NonFinAlity to rule out candidate (b) where the last syllable is footed, even though it is not stressed (see Elenbaas and Kager 1999, Hyde 2007 for further discussion). The constraint NONFInALITY outranks ALLFEET-R.

Step 1 for an 8-syllable word

\begin{tabular}{|lr||l|c|c|c|}
\hline & $/ \sigma \sigma \sigma \sigma \sigma \sigma \sigma \sigma /$ & *FoOTFoOT & PARSE- $\sigma$ & NONFINALITY & ALLFEET-R \\
\hline \hline a. $\sigma \sigma \sigma \sigma \sigma(' \sigma \sigma) \sigma$ & & 6 & & 1 \\
\hline b. $\quad \sigma \sigma \sigma \sigma \sigma \sigma(' \sigma \sigma)$ & & 6 & $1 \mathrm{~W}$ & $\mathrm{~L}$ \\
\hline c. $\quad(' \sigma \sigma) \sigma \sigma \sigma \sigma \sigma \sigma$ & & 6 & & $6 \mathrm{~W}$ \\
\hline
\end{tabular}

At the second step, we can see that the constraint *FoOTFoot must outrank ALLFEET-R. This ranking favors the ternary stress candidate (a) over the binary stress candidate (b).

Step 2 for an 8-syllable word

\begin{tabular}{|lr||l|c|c|c|}
\hline & $/ \sigma \sigma \sigma \sigma \sigma\left({ }^{\prime} \sigma \sigma\right) \sigma /$ & *FoOtFoOT & PARSE- $\sigma$ & NONFINALITY & AlLFEET-R \\
\hline \hline a. $\sigma \sigma\left({ }^{\prime} \sigma \sigma\right) \sigma(' \sigma \sigma) \sigma$ & & 4 & & $1+4$ \\
\hline b. $\quad \sigma(' \sigma \sigma) \sigma \sigma\left({ }^{\prime} \sigma \sigma\right) \sigma$ & & 4 & & $1+5 \mathrm{~W}$ \\
\hline c. $\quad \sigma \sigma \sigma\left({ }^{\prime} \sigma \sigma\right)\left({ }^{\prime} \sigma \sigma\right) \sigma$ & $1 \mathrm{~W}$ & 4 & & $1+3 \mathrm{~L}$ \\
\hline
\end{tabular}

At the third step, the derivation converges (16). Candidate (b) with an additional foot violates high-ranked *FoOTFoOT. 
Step 3 for an 8-syllable word (convergence)

\begin{tabular}{|lr||c|c|c|c|}
\hline$/ \sigma \sigma(' \sigma \sigma) \sigma(' \sigma \sigma) \sigma /$ & *FoOtFoot & PARSE- $\sigma$ & NONFINALITY & AlLFeET-R \\
\hline \hline a. $\sigma \sigma(' \sigma \sigma) \sigma(' \sigma \sigma) \sigma$ & & 4 & & $1+4$ \\
\hline b. $\quad(' \sigma \sigma)\left({ }^{\prime} \sigma \sigma\right) \sigma(' \sigma \sigma) \sigma$ & $1 \mathrm{~W}$ & $2 \mathrm{~L}$ & & $1+4+6 \mathrm{~W}$ \\
\hline
\end{tabular}

Steps 1 and 2 are identical in 9-syllable words. At step 3, the high ranked *FootFoot prefers a non-adjacent foot, generating ternary rhythm (17). At step 4, the derivation converges.

Step 3 for 9-syllable words

\begin{tabular}{|r||l|c|l|c|}
\hline$/ \sigma \sigma \sigma\left({ }^{\prime} \sigma \sigma\right) \sigma\left({ }^{\prime} \sigma \sigma\right) \sigma /$ & *FoOTFoOT & PARSE- $\sigma$ & NONFINALITY & ALLFEET-R \\
\hline \hline a. ${ }^{\prime}(' \sigma \sigma) \sigma\left({ }^{\prime} \sigma \sigma\right) \sigma(' \sigma \sigma) \sigma$ & & 3 & & $1+4+7$ \\
\hline b. $\quad \sigma \sigma \sigma\left({ }^{\prime} \sigma \sigma\right) \sigma\left({ }^{\prime} \sigma \sigma\right) \sigma$ & & $5 \mathrm{~W}$ & & $1+4 \mathrm{~L}$ \\
\hline
\end{tabular}

The constraint *FoOTFoOT, when compared to *LAPSE, has several crucial advantages. First, *FoоTFoot predicts ternary stress. Second, *FoоTFoot never determines the position of the first foot. This choice is left to alignment constraints and NONFINALITY. Third, *FootFoot never enforces footing, thus not duplicating the effect of PARSE- $\sigma$. For instance, *FoOTFoOT in combination with top-ranked FINAL-WINDOW ( $(3)$ will never mix binarity and ternarity (8).

Finally, we must also make sure that *FoOTFOOT does not replicate the pathologies of *LAPSE $(\S 4)$ or generate additional pathologies. We tested this with OT-Help 2.0 by using the same set of inputs and operations. We ran multiple separate simulations with different constraint sets. Here, we include one typology for a direct comparison with *LAPSE. (Other typologies and corresponding OT-Help files are available on the authors' websites.) The constraint set was identical, except for added NonFinAlity, and *FootFoot instead of *LAPSE. A total of 41 languages were obtained; none had foot reversals and none showed 
mixed binarity and ternarity as a function of the number of syllables left unparsed after the first step. Of these 41 languages, 17 did not foot some of the inputs (and can be ruled out on principle), 4 languages were attested single stress systems, and 6 were binary systems. The remaining 14 languages had ternary stress. All of them resembled attested ternary stress languages. These included 4 well-known ternary languages, including right-to-left, trochaic Cayuvava and left-to-right, trochaic Tripura Bangla, where a sequence of three unstressed syllables is allowed at the end of the word. The remaining 10 languages were typological gaps. They were gaps-rather than pathologies-because they resemble the attested languages in terms of directionality, foot form, and whether NONFINALITY is active.

The only place where binarity disturbs ternary rhythm in some languages is at the edge of words. These languages are not pathological, since limited binarity is found in other cases of ternary stress. Recall that Cayuvava allows for two unparsed syllables at the beginning of the word after the last foot has been built (2). These two remaining syllables are instead footed in languages like Chugach Alutiiq and Estonian, leading to limited binarity in a primarily ternary system. We confirmed that *FOOTFOOT can capture these languages, and the differences among them stem from the ranking between *FOOTFOOT and PARSE- $\sigma$ (18).

(18) Factorial typology for ternary stress with *FoOTFOOT in HS

\begin{tabular}{|c|c|c|}
\hline Language & Crucial ranking & Crucial example \\
\hline Cayuvava & $*$ FoOTFOOT $\gg$ PARSE- $\sigma \gg$ ALLFEET-R & $\sigma \sigma\left({ }^{\prime} \sigma \sigma\right) \sigma\left({ }^{\prime} \sigma \sigma\right) \underset{\leftarrow}{\sigma}$ \\
\hline Tripura Bangla & $*$ FoOTFOOT $\gg$ PARSE- $\sigma \gg$ AlLFEET-L & $\underset{\rightarrow}{('} \sigma \sigma) \sigma\left({ }^{\prime} \sigma \sigma\right) \sigma \sigma$ \\
\hline Estonian & PARSE- $\sigma \gg *$ FOOTFOOT $\gg$ ALLFEET-L & $\underset{\rightarrow}{(' \sigma \sigma) \sigma(' \sigma \sigma)\left({ }^{\prime} \sigma \sigma\right)}$ \\
\hline Chugach Alutiiq & PARSE $-\sigma \gg *$ FOOTFOOT $\gg$ ALLFEET-L & $\underset{\rightarrow}{\left(\sigma^{\prime} \sigma\right) \sigma\left(\sigma^{\prime} \sigma\right)\left(\sigma^{\prime} \sigma\right)}$ \\
\hline
\end{tabular}


One concern is that *FоOTFOOT is not supported by any pattern other than ternary stress, which is not the case for *LAPSE (Elenbaas and Kager 1999). However, *FoOTFoot has no unusual formal properties. In fact, it is formally similar to several other markedness constraints that prohibit two adjacent identical or similar structures, including the ${ }^{*} \mathrm{CC}$ constraint against adjacent consonants or OCP constraints.

We have shown that HS requires a constraint referring to constituency (as independently argued in Pruitt 2012), such as *FootFoot.

\section{Conclusions}

This squib shows that *LAPSE cannot generate ternary stress and creates pathologies in HS. The constraint *LAPSE works properly only when it can evaluate an entirely metrified string, which is impossible in HS. Only *FоOTFоOT, which refers to metrical constituents rather than the distribution of peaks and troughs, can derive ternarity. This supports an analysis based on non-adjacency of constituent edges; in HS, feet are therefore required. 


\section{References}

Crowhurst, Megan J. 1992. Minimality and foot structure in metrical phonology and prosodic morphology. Doctoral Dissertation, University of Arizona, Tucson.

Das, Shyamal. 2001. Some aspects of the phonology of Tripura Bangla and Tripura Bangla English. Doctoral Dissertation, Central Institute of English and Foreign Languages, Hyderabad.

Dresher, B. Elan, and Aditi Lahiri. 1991. The Germanic foot: Metrical coherence in Old English. Linguistic Inquiry 22:251-286.

Elenbaas, Nine, and René Kager. 1999. Ternary rhythm and the lapse constraint. Phonology $16: 273-329$.

Gordon, Matthew. 2002. A factorial typology of quantity-insensitive stress. Natural Language and Linguistic Theory 20:491-552.

Green, Thomas, and Michael Kenstowicz. 1995. The lapse constraint. In Papers from the Sixth Annual Meeting of the Formal Linguistics Society of Mid-America, ed. by Leslie Gabriele, Debra Hardison, and Robert Westmoreland, 1-15. Bloomington, IN: Indiana University.

Halle, Morris, and Jean-Roger Vergnaud. 1987. An essay on stress. Cambridge, MA: MIT Press.

Hayes, Bruce. 1995. Metrical stress theory: Principles and case studies. Chicago: University of Chicago Press.

Hewitt, Mark S. 1992. Vertical maximization and metrical theory. Doctoral Dissertation, Brandeis University, Waltham, MA. 
Houghton, Paula. 2008. Positionally licensed extended lapses. In PLC 31: Proceedings of the 31st Annual Penn Linguistics Colloquium, ed. by Joshua Tauberer, Aviad Eilam, and Laurel MacKenzie, University of Pennsylvania Working Papers in Linguistics Volume 14.1, 201-212. Philadelphia: University of Pennsylvania Working Papers in Linguistics.

van der Hulst, Harry. 2010. Word accent: Terms, typologies and theories. In Stress patterns of the world. Part II: The data, ed. by Harry van der Hulst, Rob Goedemans, and Ellen van Zanten, 3-54. Berlin: Mouton de Gruyter.

Hyde, Brett. 2007. Non-finality and weight-sensitivity. Phonology 24:287-334.

Hyde, Brett. 2009. A closer look at Iterative Foot Optimization and the case against parallelism. Ms. Washington University, St. Louis.

Hyde, Brett. 2012a. Alignment constraints. Natural Language and Linguistic Theory 30:789-836.

Hyde, Brett. 2012b. The odd-parity input problem in metrical stress theory. Phonology $383-431$.

Jesney, Karen. 2011. Positional faithfulness, non-locality, and the Harmonic Serialism solution. In Proceedings of NELS 39, ed. by Susi Lima, Kevin Mullin, and Brian Smith, 429-440. Amherst: GLSA, University of Massachusetts.

Kager, René. 1994. Ternary rhythm in alignment theory. Ms. Utrecht University. Available on Rutgers Optimality Archive, ROA 35, http://roa.rutgers.edu.

Kager, René. 2007. Feet and metrical stress. In The Cambridge handbook of phonology, ed. by Paul de Lacy, 195-227. Cambridge: Cambridge University Press.

Kager, René. 2012. Stress in windows: Language typology and factorial typology. Lingua 122:1454-1493. 
Key, Harold. 1967. Morphology of Cayuvava. The Hague: Mouton de Gruyter.

Kimper, Wendell. 2011. Locality and globality in phonological variation. Natural Language and Linguistic Theory 29:423-465.

Levin, Juliette. 1988. Generating ternary feet. Texas Linguistic Forum 29:97-113.

Liberman, Mark, and Alan Prince. 1977. On stress and linguistic rhythm. Linguistic Inquiry 8:249-336.

Martínez-Paricio, Violeta. 2013. An exploration of minimal and maximal metrical feet. Doctoral Dissertation, University of Tromsø.

McCarthy, John J. 2003. OT constraints are categorical. Phonology 20:75-138.

McCarthy, John J. 2010a. Harmonic Serialism supplement to Doing Optimality Theory. Ms. University of Massachussets Amherst. Available on Rutgers Optimality Archive, ROA 1099, http://roa.rutgers.edu.

McCarthy, John J. 2010b. An introduction to Harmonic Serialism. Language and Linguistics Compass 10:1010-1018.

McCarthy, John J. to appear. The theory and practice of Harmonic Serialism. In Harmonic Grammar and Harmonic Serialism, ed. by John J. McCarthy and Joe Pater. London: Equinox.

Pruitt, Kathryn. 2010. Serialism and locality in constraint-based metrical parsing. Phonology $27: 481-526$.

Pruitt, Kathryn. 2012. Stress in Harmonic Serialism. Doctoral Dissertation, University of Massachusetts, Amherst. 
Rice, Curt. 1992. Binarity and ternarity in metrical theory: Parametric extension. Doctoral Dissertation, University of Texas, Austin.

Rice, Curt. 2007. The roles of GEN and CON in modeling ternary rhythm. In Freedom of analysis?, ed. by Sylvia Blaho, Patrik Bye, and Martin Krämer, 233-255. Berlin and New York: Mouton de Gruyter.

Rice, Curt. 2011. Ternary rhythm. In The Blackwell companion to phonology, ed. by Marc van Oostendorp, Colin J. Ewen, Elizabeth Hume, and Keren D. Rice, volume 5, 1228-1244. Malden, MA: Blackwell.

Staubs, Robert, Michael Becker, Christopher Potts, Patrick Pratt, John J. McCarthy, and Joe Pater. 2010. OT-Help 2.0: Software package. 


\section{Notes}

*The authors would like to thank Ben Hermans, René Kager, Violeta Martínez-Paricio, Marc van Oostendorp, Clàudia Pons-Moll, Curt Rice, Keren Rice, and the anonymous reviewers.

${ }^{1}$ See Halle and Vergnaud (1987), Levin (1988) for ternary feet; Dresher and Lahiri (1991), Crowhurst (1992), Hewitt (1992), Rice (1992, 2007, 2011), Martínez-Paricio (2013) for binary solutions; and Kager (1994), Houghton (2008) for constraints on adjacent feet.

${ }^{2}$ Counterintuitively, the opposite ranking (ALLFEET-L $\gg$ AlLFEET-R) is needed in POT to capture right-to-left directionality. Elenbaas and Kager (1999:284) show that in 6syllable words, AllFeEt-L must outrank AlLFEET-R to choose (' $\sigma \sigma) \sigma\left({ }^{\prime} \sigma \sigma\right) \sigma$ instead of $* \sigma\left({ }^{\prime} \sigma \sigma\right) \sigma(' \sigma \sigma)$.

${ }^{3}$ See Hyde $(2009,2012 b)$ and Pruitt (2012) for further discussion of bidirectionality in HS.

${ }^{4}$ An anonymous reviewer asks whether *FoOTFOOT could be seen as a weaker version of $*$ CLASH ( $\equiv$ No adjacent stresses). These two constraints are fundamentally different because *FOOTFOOT refers to footing, whereas *CLASH refers to rhythm. In the constraint set with *FOOTFOOT but not *LAPSE, there is no constraint favoring foot reversals. Hence, *CLASH is never violated by any of the winning candidates. In contrast, *LAPSE triggers foot reversals on its own $(\S 4)$. 